\title{
Fine structure of Eimeria (s. 1.) vanasi merogony stages in the intestinal mucosa of cichlid fishes
}

\author{
Ilan Paperna
}

Department of Animal Sciences, Faculty of Agriculture of the Hebrew University of Jerusalem, Rehovot, 76-100, Israel

\begin{abstract}
Electron microscopic studies of the gut of Oreochromis aurea $\times$ nilotica fry infected with Eimeria (s. l.) vanasi Landsberg \& Paperna, 1987 revealed merozoites contained in epicytoplasmic parasitophorous vacuoles bulging from the brush border of their epithelial host cells. Merozoites and early meronts were contained in parasitophorous vacuoles within both the host cell cytoplasm and the host cell nucleus. Special structures are formed at the juncture of the parasitophorous vacuole and the host cell cytoplasm. Before release from the parent meront's parasitophorous vacuole, some of the newly formed merozoites produce further daughter merozoites by endogenous division.
\end{abstract}

\section{INTRODUCTION}

Eimeria (s. l.) vanasi Landsberg \& Paperna, 1987 parasitizes the intestinal epithelium of a variety of cichlid fish species in Israel and South Africa (Landsberg \& Paperna 1987). Developing and dividing meronts and gamonts are either intracytoplasmic or epicytoplasmic, e.g. developing like piscine coccidia of the genus Epieimeria Dykova \& Lom, 1981, contained in parasitophorous vacuoles (PV) in the microvillous apical end of the epithelial cell, bulging above the epithelial layer. Intracytoplasmic and epicytoplasmic meront progenies were found to be the same, and consisted of from 2 to 32 merozoites. It was also found that within the epithelial cells merozoites could develop either in the cytoplasm or in the host cell nucleus (Landsberg \& Paperna 1987). Ultrastructural observations (Paperna \& Landsberg 1987) revealed the presence of numerous tubuli in the host cell cytoplasm extending from funnels located at the border of the PV. Such tubuli are most developed and abundant in PVs containing gamonts. The fine structure of the gamonts was presented by Paperna (1990). In the present communication the fine structure of meronts and merozoites is reported and discussed.

\section{MATERIALS AND METHODS}

Infected fry of Oreochromis aurea $\times$ nilotica (the culture 'tilapia') were obtained from hatcheries in Beit
Shaan valley, Israel. Infection was verified by examining Giemsa-stained smears prepared from segments of the intestine in a light microscope (LM) by methods described earlier (Landsberg \& Paperna 1987). For transmission electron microscopy (TEM), pieces from the anterior gut were fixed in $2.5 \%$ glutaraldehyde in $0.1 \mathrm{M}$ cacodylate buffer, $\mathrm{pH} 7.4$, for $24 \mathrm{~h}$ at $4{ }^{\circ} \mathrm{C}$. After repeated washes in the buffer, the material was postfixed in $1 \%$ osmium tetroxide in buffer, for $1 \mathrm{~h}$. After rinsing in the buffer, the material was dehydrated in ethanol and embedded in Epon. Thin sections cut by a Reichert ultratome with diamond knife were stained on a grid with uranyl acetate and lead citrate and examined with a Joel 100CX TEM.

\section{RESULTS}

\section{Epicytoplasmic merogony stages}

Epicytoplasmic merogony stages (Figs. 1 to 8) bulge from the microvillous surface of the gut mucosa epithelial cells. They are enclosed in a parasitophorous envelope (PE) derived from the merging of the epithelial cell boundary with the PV limiting membrane (Fig. 5). Small projections on the outer surface of the PE are formed by tight foldings in the $\mathrm{PE}$ membranes (Fig. 5).

Epicytoplasmic PVs form 2 types of junctures with the cytoplasm of the host cell. The PV with the first type juncture measures 4.0 to $5.4 \times 4.0$ to $4.5 \mu \mathrm{m}$ (Figs. 1 to 

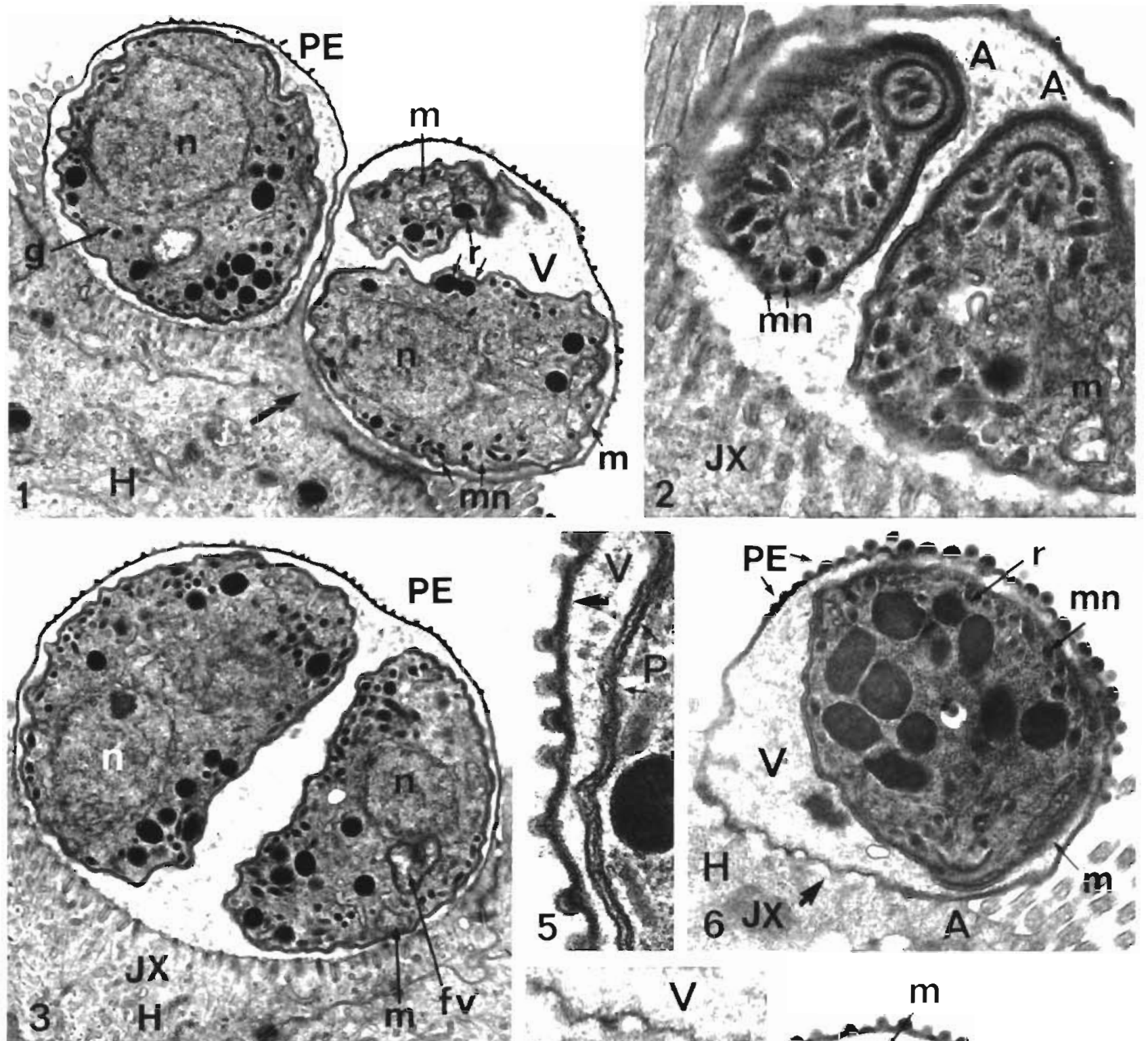

$$
\text { is }
$$

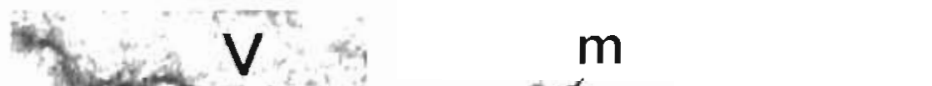

v. n 12

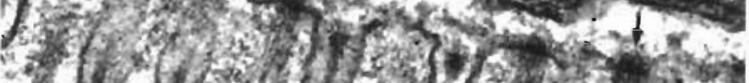
1. -

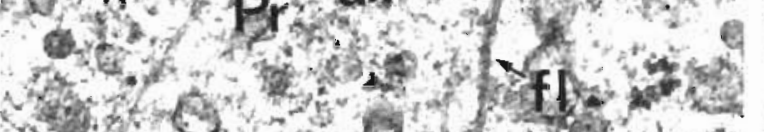

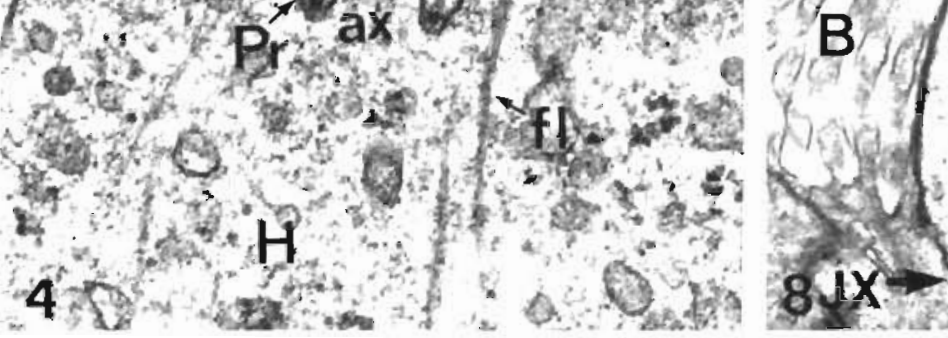

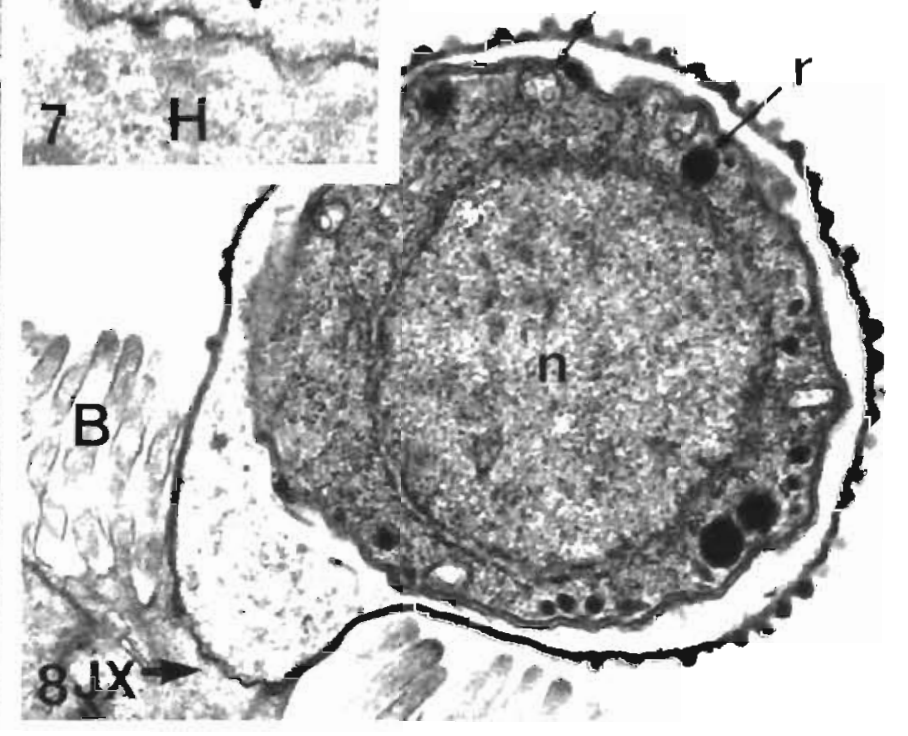


3). At the contact zone the host cell cytoplasm forms numerous tightly-packed elongated, deep protrusions into the host cell cytoplasm. Each protrusion contains an axial filament or microtubule. Between the protrusions long microfibrils or filaments in the host cell cytoplasm congregate into 'brush-like' bundles (Fig. 4). The protrusions and the bundles are absent in what appears to be the center of the PV/host cytoplasm contact zone (Fig. 1). The PV with the second type juncture measures 2.5 to $3.5 \times 2.2$ to $3.0 \mu \mathrm{m}$ (Figs. $6 \&$ 8). The PV wall bordering the host cell cytoplasm forms undulations or regularly spaced shallow projections containing an osmiophilic substance (Figs. 6 \& 7).

The PVs contain 1 (Figs. 1, $6 \&$ 8) or 2 (Figs. $2 \& 3$ ) merozoites either bound by a triple-membrane pellicule (Figs. 2, 4 \& 5), or having a 2-membrane boundary (Figs. $1 \& 3$ ). The merozoites contain an apical complex consisting of a conoid, electron-dense rhoptries and micronemes (Figs. 2, $3 \&$ \& 6 ). Their round nucleus contains homogeneously distributed chromatin with an apparently eccentric nucleolus (Fig. 3). The cytoplasm of some of the merozoites reveals peripherally arranged mitochondria, a Golgi apparatus and endoplasmic reticulum (ER) (Figs. 1, 4 \& 8).

\section{Intracytoplasmic merogony stages}

Gut sections reveal PVs in the cytoplasm of epithelial cells. Some of the PVs contain from one to several merozoites measuring 7 to $8 \times 2$ to $4 \mu \mathrm{m}$ merozoites (Figs. 9 to 13), a few of them still connected to the meront's residue (Figs. $9 \& 10$ ). A few others contain young, $4 \times 3 \mu \mathrm{m}$ meronts (Fig. 14), while still others contain clusters of 5 or more free 4.0 to $5.0 \times 1.5$ to $2.0 \mu \mathrm{m}$ merozoites still in their parent PV (Fig. 15). The wall of the PV containing young meronts consists of a single fine membrane (Fig. 14), while the wall of the PV containing merozoites is made up of 3 parallel membranes (Figs. 11 \& 13). In some of the latter PVs ground substance is deposited between the 2 inner membranes (Fig. 13). The PV wall is interrupted by a few (Fig. 9) or many funnels (Fig.13). Intracytoplasmic tubuli are, however, absent. All merozoites are bounded by a trilayered pellicle and have a developed apical complex with rhoptries and micronemes (Figs. 9 to $13 \& 15$ ).
The meront residue (Fig. 10) and the young meronts (Fig. 14) are each bounded by a single membrane. The young meront contains large food vacuoles, clusters of apparently extracted lipid vacuoles and rudiments of an apical complex (Fig. 14). The meront and merozoite nuclei contain heterochromatin with a rounded nucleolus.

\section{Endogenous division of merozoites}

The intracytoplasmic merozoites (Figs. 9 to 13) contain an anlage of daughter merozoites. Each anlage consists of an inner membrane complex, a developing conoid (Figs. 12 \& 13), a relatively large rhoptry anlage (Figs. 10, 11 \& 12) or several rhoptries (Fig. 12), a mitochondrion, a Golgi complex and an extension of the parent merozoite nucleus (Figs. $10 \& 13$ ).

\section{Intranuclear infection}

Intranuclear infections are seen with single $6.0 \times$ $2.5 \mu \mathrm{m}$ merozoites (Fig. 16), and with young $3.5 \times$ $4.0 \mu \mathrm{m}$ meronts (Fig. 17). Parasites located in the nucleus are contained in a PV bounded by a trilaminated wall (Fig. 18). The host's nuclear chromatin remains homogeneous, apparently intact. The merozoite is similar to those seen infecting the cytoplasm, with a trilaminated pellicule, rhoptries and micronemes, mitochondria and a Golgi complex. The young meronts still retain rudiments of an apical complex and contain large food vacuoles, several large, peripherally located mitochondria, a nucleus and a few lipid vacuoles.

\section{DISCUSSION}

Epicytoplasmic, intracytoplasmic and intranuclear infections found to occur simultaneously in intestines of the same individual cichlid fish hosts have been interpreted to belong to the same species, Eimeria s.l. vanasi (Landsberg \& Paperna 1987). This view is challenged by the recent findings of Molnar (1989) showing that concurrent epicytoplasmic and intracytoplasmic infections in the same individual hosts are caused in

Figs. 1 to 8. Eimeria (s. 1.) vanasi. Figs. 1 to 3. Merozoites in epicytoplasmic PV (V) with protrusions at the juncture with the host cell cytoplasm (H). A: apical complex with the conoid; fv: food vacuole; g: Golgi apparatus; H: host cell cytoplasm; JX: juncture zone; $\mathrm{m}$ : mitochondria; mn: micronemes; n: nucleus; PE: parasitophorous envelope; $\mathrm{r}$ : rhoptries; bold arrow: protrusion-free zone. (Fig. $1 \times 10500$; Fig. $2 \times 26700$; Fig. $3 \times 13600$ ). Fig. 4. Enlargement of the juncture showing details of the protrusions (Pr) with the axial filament (ax) and the microfibrils (fl) terminating in brush-like bundles (b). See also details of the merozoite pellicle (P) within the PV $(\times 46200)$. Fig. 5. Details of the PE and the merozoite pellicle (P); V: PV lumen $(\times 46200)$. Figs. 6 \& 8. Epicytoplasmic PV (V) containing merozoite, with shallow projections at the juncture (JX). B: brush border microvilli (Fig. $6 \times$ 20300; Fig. $8 \times 23100)$. Fig. 7 . Enlarged view of the PV(V)/host cell cytoplasm (H) juncture $(\times 40600)$ 

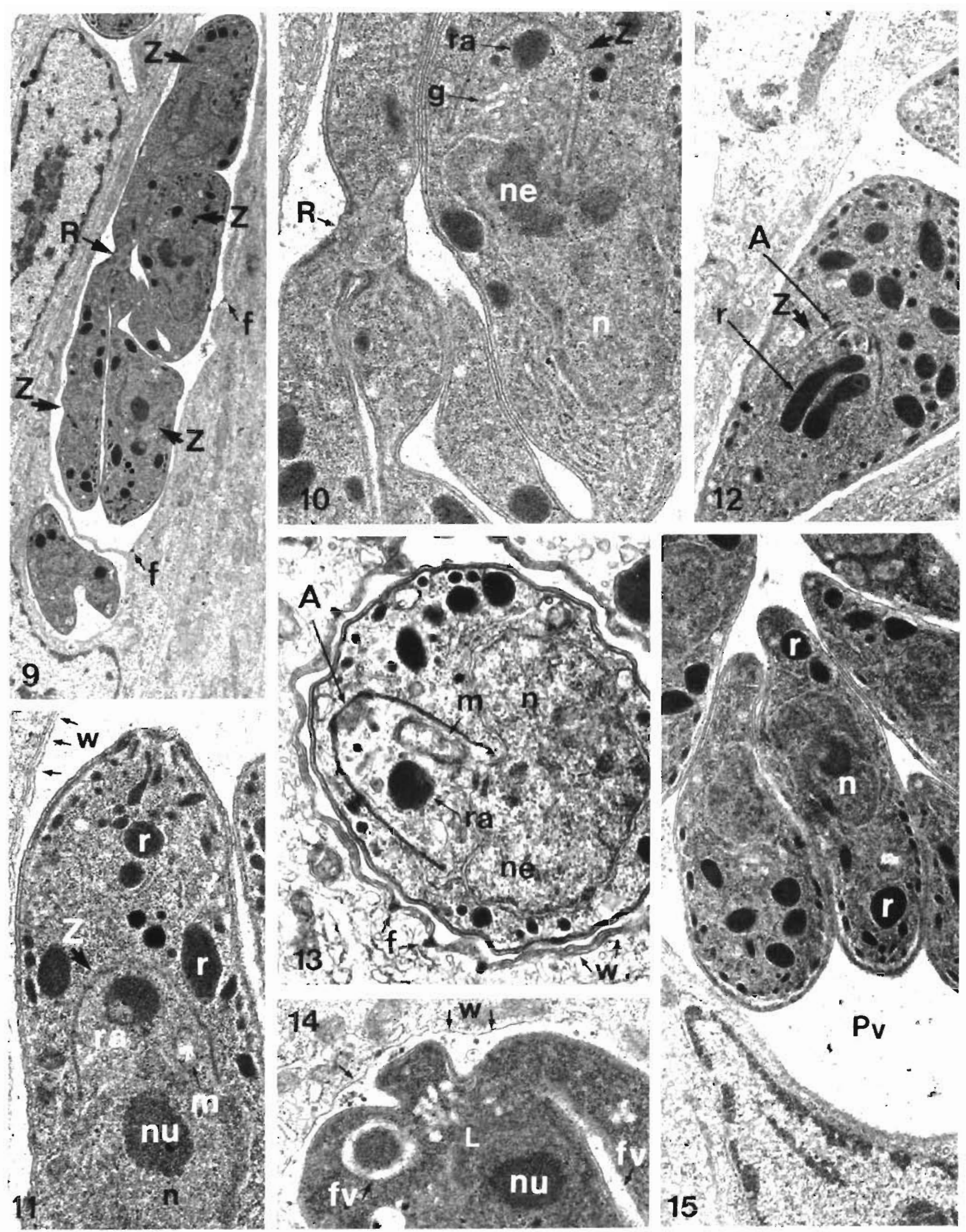

13 fots
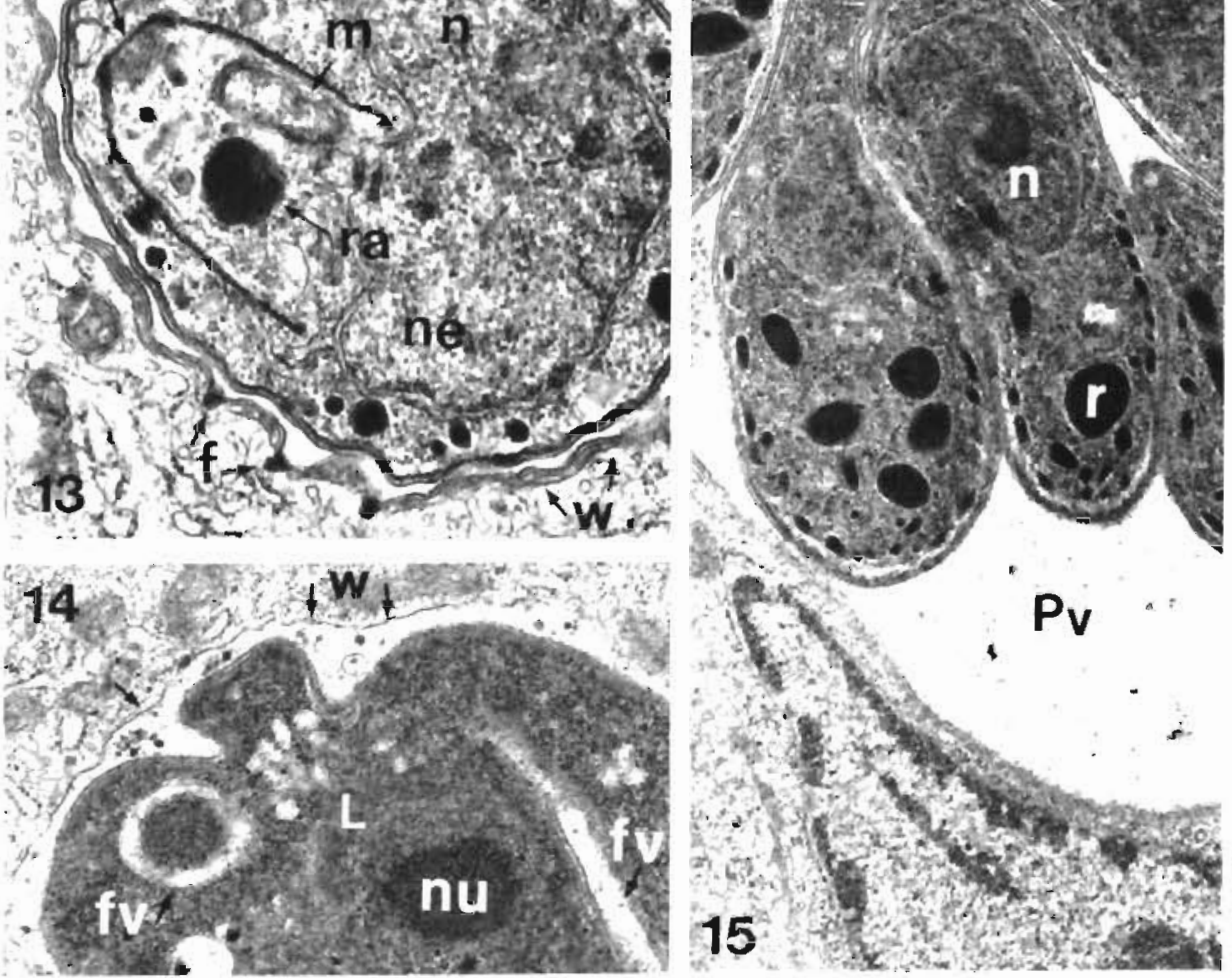

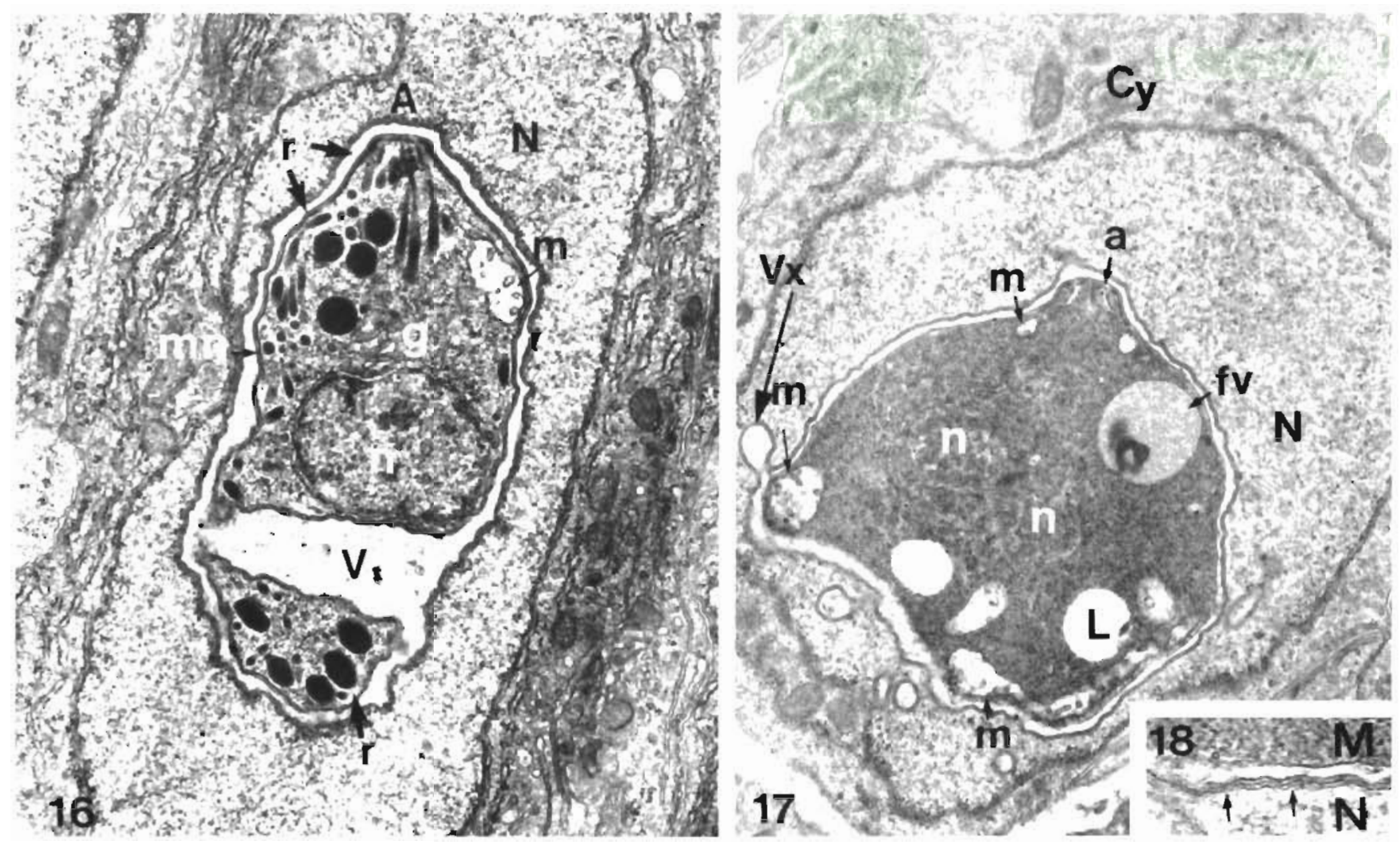

Figs. 16 to 18. Eimeria (s. l.) vanasi. Figs. 16 \& 17 Intranuclear infections Fig 16 Merozoite (× 14400$)$ Fig. 17 Young meront with vestigial apical complex (a); note extensions of the PV (VX) N: host cell nucleus; Cy host cell cytoplasm; other abbreviations as in previous figures. $(\times 14800)$. Fig. 18. Enlargement of the borders between the meront $(\mathrm{M})$, the PV wall (arrows) and the host nucleus $(\times 29699)$

fact by 2 distinct species. TEM studies of developing $E$. vanasi gamonts, however, reveal an actual process of migration of macrogamonts with therr PV through the brushborder of the host epithelium (Paperna 1990, and unpubl.). Shift from an epicytoplasmic site (of gamonts) into an intracytoplasmic location (of sporulating oocysts) has been also described in E. angunllae (Dykova \& Lom 1981). Ultrastructural findıngs on merogony stages presented in this communication do not contribute enlightening new data to prove or disprove conspecifity. This issue is currently being examined by an experimental study The latter study is also likely to define the actual number and sequences of merogony generations, which could not be so far established through past and present studies.
Merozoltes within PV with difterent kind of junctures to the host cell cytoplasm may represent different developmental generations. An interpretation of the fine structure of the presently reported first type of epicytoplasmic PV boundary/host cell cytoplasm juncture is difficult: such a juncture has not been seen in any other coccidian infections. The projections seen alternating with fibrillar bundles at the PV boundary could be the microvillous brush border of the host cell, modified, compressed or displaced by the expanding PV of the growing parasites. The protrusions and fibrils appear to be absent in the center of the PV boundary contact zone, the site at which the parasite apparently enters and undergoes its pnmary development beneath the host cell brush border. The protrusions with their

Figs. 9 to 15. Eimeria (s. 1.) vanasi. Fig. 9. Merozoites connected to a meront residue (R), with anlagen of daughter merozoites (Z), in an intraepithelial PV lined by a trilayered wall with funnels (f) $(\times 5700)$. Figs. 10 to 13. Enlargements of merozoltes in a PV lined by a trilaminated boundary ( $w$ ) with funnels (f), showing a meront residue (R), merozoites' rhoptnes ( $\mathrm{r}$ ), micronemes (mn), nucleus (n) and anlage of daughter merozoite growing from an extension of the parent cell nucleus (ne), with rudiments of conoid (A), Golgi apparatus $(\mathrm{g})$, mitochondrion $(\mathrm{m})$ and rhoptries $(\mathrm{r})$ or rhoptry anlagen (ra). nu. nucleolus. (Fig. $10 \times 19800$. Fig. $11 \& 12 \times$ 17000 ; Fig. $13 \times 22300$ ). Fig. 14 . Young meront enclosed in PV bounded by a single membrane (w) contans a nucleus with a prominent nucleolus (nu), food vacuoles (fv) and small lipid vacuoles (L) $(\times 16700)$ Fig. 15 PV (Pv) with a formation of 5 differentiated merozoltes $(\times 12000)$ 
axial filaments are somewhat reminiscent of the protrusions incorporated into the primary cyst walls of Sarcocystis spp. (Mehlhorn et al. 1976). Arguments for phylogenetic homology between the PV/host cell cytoplasm juncture and the sarcocyst wall may be very vague, but there is undoubtedly a functional analogy in that they are both routes for metabolic exchange between the host and parasite cells. The small projections on the PE do not seem to be vestiges of microvilli. These projections enlarge the area of the contact between the epiplasmic PV and the intestinal lumen and suggest the existence of some sort of metabolic exchange with the extracellular intestinal environment. Such projections occur in one undescribed epieimerian piscine species (Boulard \& Blanc 1985), but are absent in other piscine (Einutida anyuillde, ivioindr \& Baska 1986; Epieimeria isabellae, Daoudi et al. 1985; Goussia zarnowskii, Jastrzebski \& Komorowski 1990) and reptilian (Acroeimeria lineri, Paperna 1989) species. In a previous communication (Paperna \& Landsberg 1987) the contact boundary of a PV containing a single nucleate meront was seen to include finger-like extensions into the host cell cytoplasm which were interpreted as vestiges or rudiments of the tubular system funnels. Similar finger-like extensions occur at the PV contact boundary of Epieimeria anguillae (Molnar \& Baska 1986), E. isabellae (Daoudi et al. 1986) and G. Zarnowskii (Jastrzebski \& Komorowski 1990). These structures may have developed from the shallow depressions seen at the contact zone of the presently reported second type of epicytoplasmic PV boundary. If this is the case then the finger-like processes may be primordia, not vestiges of the tubular system funnels.

Endogenous formation of merozoites within merozoites similar to the process of endodyageny found in cyst-forming coccidia, such as Sarcocystis, Toxoplasma and Cystoisospora (Scholtyseck 1973, Hilali et al. 1979, Ferguson et al. 1980), seems to comprise a distinct stage in the sequence of asexual reproductions of Eimeria vanasi. Both intracytoplasmic and epicytoplasmic PVs containing 2 merozoites are frequently observed in LM-studied smears and sections of E. Vanasi-infected intestines (Landsberg \& Paperna 1987). The merozoite couples seen within epicytoplasmic PVs (Figs. 2 \& 3) seem to have been formed by the same process. Multiplication by endodyogeny is also found in Eimeria magna (Danforth \& Hammond 1972). In the latter, several merozoite anlagen occur within multinucleate merozoites (also termed 'sporozoite shaped schizonts') while in E. vanasi such merozoites always contain only a single nucleus. All observed merozoites contained only one merozoite anlagen. However, ultrathin sections of merozoites undergoing endodyogeny often reveal only one of the
2 merozoite anlagen (Hilali et al. 1979, Daly \& Markus 1981)

Intranuclear endogenous development is found in a number species of piscine coccidia (Lom \& Dykova 1982, Daoudi et al. 1987). It is relatively common among coccidia species infecting amphibians and reptiles, rare in those infecting mammals and thus far absent in those infecting birds (Pellerdy 1974). All intranuclear piscine species described to date develop exclusively in the host cell nucleus. A versatility in the site of development may nevertheless be implied, since, in cell culture, the intranuclear species found in cattle, Eimeria alabamensis, infects the host cell cytoplasm rather than its nucleus (Sampson \& Hammond 1972).

\section{LITERATURE CITED}

Boulard, Y., Blanc, E. (1985). Presence d'une coccidie susepitheliale dans l'intestin de Labrus berggylta (Téléostéen). Society of Protozoology Abstracts, No. 36

Daly, T. J. M., Markus, M. B. (1981). Enteric multiplication of Isospora felis by endodygeny. Electron microscopy Soc. South. Afr., Proceedings 11: 99

Danforth, H. D., Hammond, D. M. (1972). Stages of merogony in multinucleate merozoites of Eimeria magna. J. Protozool. 19: 454-457

Daoudi, F., Marques, A., Bouix, G. (1985). Ultrastructure d'Epieimeria isabellae Lom et Dykova, 1982 Coccidie épicellulaire parasite intestinal du poisson Teleosteen Conger conger Linné, 1758. Society of Protozoology Abstracts, No. 35

Daoudi, F., Radujkovic, B., Marques, A., Bouix, G. (1987). Nouvelles espèces de Coccidies (Apicomplexa, Eimeridae) des genres Eimeria Schneider, 1875, et Epieimeria Dykova et Lom, 1981, parasites de poissons marines de la baie de Kotor (Yougoslavie). Bull. Mus. Hist. nat. Paris, 4e ser, 9 (section $A$, no. 2) : 321--332

Dykova, I., Lom, J. (1981). Fish coccidla: critical notes on life cycles, classification and pathogenicity. J. Fish Dis. 4: 487-505

Ferguson, D. J. P., Birch-Andersen, A., Hutchinson, W. M., Siim, J. Chr (1980). Ultrastructural observations showing enteric multiplication of Cystoisospora (Isospora) felis by endodyogeny. Z. Parasitenkde 63: 289-291

Hilali, M., Ghaffar, F. A., Scholtyseck, E. (1979). Ultrastructural study of the endogenous stages of Isospora canis (Nemesern, 1959) in the small intestine of dogs. Acta Vet. Acad. Sci. Hung. 27 233-243

Jastrzębski, M., Komarowski, Z. (1990). Light and electron microscopic studies on Goussia zarniwskii (Jastrzębski. 1982): an intestinal coccidium parasitizing the three-spined stickleback, Gasterostreus aculeatus. J. Fish Dis. 13: 1-12

Landsberg, J H., Paperna, I. (1987). Intestinal infections by Eimeria s.l. vanasi n. sp. (Eimeriidae, Apicomplexa, Protozoa) in cichlid fish. Ann. parasitol. Hum. Comp. 62: 283-293

Lom, J., Dykova, I. (1982). Some marine fish coccidia of the genera Eimeria Schneider. Epieimeria Dykova \& Lom and Goussia Labbe. J. Fish Dis. 5: 309-321

Mehlhorn, H., Hartley, W J., Heydorn, A. O. (1976). A comparative ultrastructural study of cyst walls of 13 Sarcocystis species. Protistologica 12:451-467 
Molnar, K. (1989). Nodular and epicellular coccidiosis in the intestine of cyprinid fishes. Dis. aquat. Org. 7: 1-12

Molnar, K. Baska, F. (1986). Light and electron microscopic studies on Epieimeria anguillae (Leger \& Hollande, 1922), a coccidium parasitizing the European eel. Anguilla anguilla L. J. Fish Dis. 9, 99-110

Paperna, 1. (1989). Ultrastructure of Eimeria (s. 1.) sp. infecting the microvillar zone of the intestinal epithelium of geckoes. Ann. Parasitol. Hum. Comp. 64: 89-99

Paperna, I. (1990). Fine structure of the gamonts of Eimeria (s. 1.) vanasi, a coccidian from the intestine of cichlid fishes. Dis. aquat. Org. 9: 163-170

Responsible Subject Editor: W. Körting, Hannover, Germany
Paperna, I., Landsberg, J. H. (1987). Tubular formations extending from parasitophorous vacuoles in gut epithelium of cichlid fish infected by Eimeria (s. l.) vanasi. Dis. aquat. Org. 2: 239-242

Pellerdy, L. P. (1974). Coccidia and coccidiasis, 2nd edn. Verlag Paul Parey, Berlin

Sampson, J. R., Hammond, D. M. (1972). Fine structural aspects of development of Eimeria alabamensis schizonts in cell cultures. J. Parasitol, 58: 311-322

Scholtyseck, E. (1973). Die Deutung von Endodygeny und Schizogonie bei Coccidien und anderen Sporozoen. Z ParasitenKde 42: 87-104

Manuscript first received: May 28, 1990

Revised version accepted: February 4, 1991 